\title{
Phonological recoding and lexical access
}

\author{
EILEEN DAVELAAR \\ University of Reading, Reading, England RG6 $2 A L$ \\ MAX COLTHEART \\ Birkbeck College, Malet Street, London, England \\ DEREK BESNER \\ University of Reading, Reading, England RG6 $2 A L$ \\ and \\ JON TORFI JONASSON \\ University of Iceland, Reykjavik, Iceland
}

\begin{abstract}
Four experiments are reported that examine the effects of homophony (e.g., SAIL/SALE) on response latency in a lexical decision task. The results indicated that an effect of homophony was evident only if the nonword distractors consisted of legal, pronounceable strings (e.g., SLINT), but that this effect disappeared if the nonwords sounded like English words (e.g., BRANE). An optional encoding strategy is proposed to account for this differential effect. It is suggested that while both graphemic and phonemic encoding occurred simultaneously, naive subjects tended to rely on the outcome of the phonological route. However, when such reliance produced a high error rate (i.e., when the nonwords sounded like English words), these subjects were able to abandon a phonological strategy and rely on the graphemic encoding procedure instead. Two further aspects of the results are of interest. First, the less frequent member of a homophone pair was slower when compared with a control item if the nonword distractors were of the SLINT type, but not different if they were of the BRANE type. The high-frequency members did not differ from their controls in either nonword environment. Second, in a homophone "repetition" experiment, the frequency order of presentation within pairs of homophones (i.e., the high-frequency member followed by the low-frequency member, or vice versa) had a substantial effect. A spelling recheck procedure and a response-inhibitory mechanism are postulated to incorporate these effects into a dual-encoding direct-access model of word recognition.
\end{abstract}

In recent years, a lively debate has developed concerning the nature of the information a reader extracts from a printed word that enables him ultimately to understand the meaning of that word. If we suppose that every reader has acquired a store of information about the words of his language (we shall term this his internal lexicon), such that every word has a separate entry in this store under which are listed all the details concerning the word's meaning, spelling, and pronunciation, then the debate can be characterized as centering on the question of how a reader gains access to the information in this internal dictionary store. Several suggestions have been advanced.

One proposes that the reader must first translate the visual information of the printed word into a corresponding phonological representation and that it is this phonological code that is then used to gain access to the word's lexical entry. Support for this

Requests for reprints should be sent to Eileen Davelaar, Department of Psychology, Reading University, Reading, England RG6 2AL. view comes from Bloomfield (1942), Gough (1972), and Rubenstein, Lewis, and Rubenstein (1971), among others. A second suggestion proposes that, on the contrary, no phonological recoding of the printed word is required and that lexical access proceeds directly using the visual representation. This contrasting view has been supported by Baron (1973), Bower (1970), and Kolers (1970). A third view, incorporating both visual and phonological access, has been characterized as a race model by Meyer, Schvaneveldt, and Ruddy (1974a) and as a model of cooperation by Coltheart, Davelaar, Jonasson, and Besner (1977).

While a good deal of evidence has been advanced in support of each of the above viewpoints, it is difficult to evaluate the relevance of much of this evidence. It is our view that a number of the experimental tasks from which the supporting data have been drawn are not logically appropriate and therefore cannot necessarily address the question concerning the nature of the lexical access code. We have advanced this argument elsewhere (Coltheart et al., 1977) and make the point here again briefly. It is our objection that a variety of 
the tasks employed can be successfully performed by the subject without involving the use of his or her lexical store. Such tasks as same-different judgments, rhyming judgments, tachistoscopic recognition, and naming-latency experiments do not logically require the subject to make use of lexical knowledge, and therefore, data obtained from these tasks cannot be considered as admissible evidence in the debate.

One task that we feel is not subject to the above objections, and that provides the data to be discussed below, is the lexical decision task. Here, the subject is required to discriminate letter strings that are English words from letter strings that are not. To perform this task successfully, it is logically necessary that the subject consult his store of English words, that is, his internal lexicon, in order to discover whether a given letter string is contained in it or not. We would like to restrict this argument, however, to cases where the letter string under consideration complies with the orthographic rules of English. A subject presented with the string BRHND can reject this item as an English word on the basis of orthographic legality alone, since English does not allow such a combination. If presented with a string like SLINT, however, a subject cannot reject such an item on the basis of the rules of English orthography alone and must consult his lexicon to determine its presence or absence. An examination of the data obtained from this task is therefore valid in order to determine the nature of the lexical access code.

While this task has been used extensively to investigate such phenomena as context effects (Meyer, Schvaneveldt, \& Ruddy, 1974b), repetition effects (Scarborough, Cortese, \& Scarborough, 1977), hemispheric effects (Cohen \& Freeman, in press; Marcel \& Patterson, in press), and the lexical access procedure (Coltheart et al., 1977; Rubenstein et al., 1971), only a few papers in the literature deal with the lexical access code per se. A paper by Rubenstein et al. (1971) was the first of these.

Rubenstein et al. (1971) compared the decision times of subjects to two types of words and to two types of nonwords. The words consisted either of items that were homophones, such as SAIL (SALE), or of items that were not homophones, such as TREE. Similarly, the nonwords were either homophonous with an English word, for example, BRANE, or they were not, for example, SLINT. The data indicated that the subjects took longer to decide that homophones were words than to decide that nonhomophones were words; also, the subjects took longer to reject pseudohomophones such as BRANE than to reject nonpseudohomophones such as SLINT. On the basis of these results, Rubenstein et al. (1971) suggest that the lexical access code is a phonological one. Their argument runs as follows.

A printed letter string is first recoded into a phonological representation and this representation is then used to discover whether or not a corresponding entry exists in the internal lexicon. The procedure by which this investigation is carried out is characterized as a search process, proceeding from high- to lowfrequency items. When an entry has been successfully located, the search terminates and a positive response results. If no entry is found, the search terminates only after every entry has been examined. Since pseudohomophones such as BRANE will result in an entry's being located, only a spelling recheck with the stimulus will allow this item to be correctly rejected. Since the spelling recheck operation results in some time cost before the search can be recommenced, these items present slower decision times than nonpseudohomophones for which no corresponding entries exist. Similarly, in the case of homophones, sometimes the located entry will be the incorrect one and again only a spelling recheck will indicate whether the search has been successful. If it has not, the search must continue until the correct entry has been found, and again, some time cost has been incurred in the process such that homophones present slower decision times than their nonhomophonic counterparts. Note that, if search is serial and proceeds from high- to low-frequency items as suggested, then slower reaction times to homophones should only result if the item in question is the less frequent member of a pair. The high-frequency member of a pair would not suffer from the location of an incorrect entry. Rubenstein et al. (1971) reported that indeed the slower reaction times for homophones held only for the less frequent member of a pair.

Unfortunately, several aspects of the stimuli employed by Rubenstein et al. (1971) are open to criticism. First, the homophones and nonhomophones, which were used as comparison groups, were not equated on such factors as part of speech and word frequency, both of which have been shown to affect lexical decision times (e.g., Forster \& Chambers, 1973; Scarborough \& Springer, Note 1). In addition, with respect to the nonwords, no effort was made by Rubenstein et al. (1971) to equate the pseudohomophones for visual similarity, and it may well be that those items that sound like English words also look more like English words than those items that do not sound like English words.

Incorporating these criticisms into their design, Coltheart et al. (1977) repeated the Rubenstein et al. (1971) experiment and obtained somewhat different results. While the decision times in the Coltheart et al. experiment to pseudohomophones like BRANE were again reliably slower than to nonpseudohomophones like BRONE (controlled for visual similarity), the decision times to the less frequent members of pairs of homophones (e.g., SAIL) were no different than the decision times to a set of matched nonhomophones controlled for frequency and part of speech. Coltheart et al. (1977) therefore argue that, while phonological recoding may play a role in the rejection of nonword 
items, no evidence presently exists to suggest that a similar recoding is carried out for words.

A lexical decision experiment reported by Meyer et al. (1974a) also attempted to address the issue of phonological recoding in lexical access. Meyer et al. examined decision times to words under a variety of conditions. In one of these conditions, reaction times to words like COUCH were observed when they were preceded by words that shared graphemic but not phonemic similarities, for example, TOUCH. Meyer et al. found that under these circumstances the decision time to $\mathrm{COUCH}$ was slower than when it was preceded by a totally dissimilar word such as BREAK. On the basis of this result, Meyer et al. (1974a) proposed an encoding-bias model such that when a presented item ends in the same letters as the one preceding it, the subject will have a tendency to encode that string using the same set of grapheme-to-phoneme correspondence rules just previously applied. Therefore, an initial encoding of $\mathrm{COUCH}$ when it was preceded by TOUCH will produce an incorrect representation. To avoid making an error, the string requires a second recoding using a different set of rules that will then produce a correct response. The time cost of the second recoding is reflected in the longer reaction times observed. While this evidence is highly suggestive of phonological recoding, it must be noted that Becker, Schvaneveldt, and Gomez (Note 2), using a similar set of stimuli, were not able to find reliably similar results, and so this evidence must be held in question.

Evidence against the phonemic recoding hypothesis in lexical access comes from a recent study by Frederiksen and Kroll (1976). Their argument is based on a comparison between those factors that affect naming latency and those factors that affect lexical decision times. The assumption on which their position rests states that if phonological recoding occurs prior to lexical access, then those factors that affect naming time must also affect lexical decision time in the same way. For example, they predict that if the number of letters in an item can be shown to affect the time required to begin to say that item, then that factor should also affect lexical decision times if phonemic recoding occurs. Their results demonstrated that none of the factors that were observed to affect naming latencies affected lexical decision times (e.g., number of letters, size of initial consonant cluster, and complexity of vowel translations). Frederiksen and Kroll therefore concluded that phonemic recoding is not a prerequisite for lexical retrieval.

We would like to point out, however, that the basic assumption of Frederiksen and Kroll (1976) is not necessarily a valid one. We have detailed our objections elsewhere (Coltheart, Jonasson, Davelaar, \& Besner, Note 3 ) and state only the major features here. Frederiksen and Kroll's assumption is dependent on the equation between the phonological representation resulting from the recoding of a letter string and the articulatory representation required for naming that string. The equation of the two representations seems to us a misleading one, and while it may be true, there is no evidence to suggest that it must be true (see also Forster \& Chambers, 1973). It is entirely possible that the two codes are independent and that those factors that affect the construction of one do not affect the construction of the other.

Frederiksen and Kroll (1976) reject the distinction between the two codes on the grounds that, while the size of the initial consonant cluster in a letter string affected the onset of articulation, the size of the final consonant cluster did not. If phonological recoding occurs prior to articulation, they argue, then the size of the final consonant cluster should also have demonstrable effects on naming latencies, since the construction of such a representation should take longer. This would be true only if the whole string were recoded before the onset of articulation and this is not a necessary prerequisite for naming. The final letters in a string may be recoded during the articulation of the initial letters, and so, the complexity of the final consonant cluster would not be reflected in the onset of articulation time. If we accept that a distinction can be drawn between a phonological code and an articulatory code, then Frederiksen and Kroll's (1976) evidence against phonological recoding cannot be accepted as definitive.

We will now consider the data from several tasks other than the lexical decision task that also require lexical access for their successful performance. Meyer and Ruddy (Note 4) devised a task in which subjects were asked to classify a letter string as belonging or not belonging to a prespecified category on the basis of either the letter string's spelling or the letter string's pronunciation. For example, following the question, "Does this sound like a fruit?", the subjects were presented with PEAR, PAIR, or TAIL, which required "yes," "yes," and "no" responses, respectively. If these same items were presented following the question, "Is this a fruit?" (the spelling task), the stimuli required "yes," "no," and "no" responses, respectively. Meyer and Ruddy (Note 4) observed that the "yes" responses to category members (PEAR) were faster in the pronunciation task than in the spelling task and, in contrast, that the "no" responses to nonmembers (TAIL) were faster in the spelling task than in the pronunciation task. With respect to the pseudomembers (PAIR), the "yes" responses to these items were slower than the "yes" responses to category members in the pronunciation condition, and similarly, the "no" responses to these items were slower than the "no" responses to nonmembers in the spelling task.

Meyer and Ruddy (Note 4) and Meyer and Gutschera (Note 5) proposed a dual-encoding race model to account for these results. They suggest that graphemic 
and phonemic encoding always occur and that each of these representations is used to search lexical memory in parallel such that either one may find a match before the other. The difference between the results in the two tasks lies in "the stopping rule for making a response" (Meyer \& Gutschera, Note 5, p. 8). In the pronunciation task, "yes" responses can be made on the basis of a successful outcome from either the graphemic or the phonemic search, while "no" decisions cannot be made on the basis of a negative outcome from the graphemic search alone, since items that are not spelled like a fruit sometimes do in fact sound like a fruit (e.g., PAIR). In contrast, the spelling task, "yes" decisions can be based only on the outcome of the graphemic search if errors are to be avoided, while "no" decisions can be made on the basis of either the graphemic or the phonemic search, since items that do not sound like a fruit cannot be spelled like a fruit and items that are not spelled like a fruit also cannot be fruits. Considering the pseudomembers (PAIR), in the pronunciation task the "yes" response requires awaiting the outcome of the phonemic search since a "no" response would be an error, and in the spelling task the "yes" response requires awaiting the outcome of the graphemic search since in this case a "yes" response to PAIR would be an error.

A dual-encoding race model, therefore, correctly predicts the results observed. Whenever a decision can be made on the basis of either the graphemic or the phonemic search, the response time will be faster on average than if a response must await the outcome of only one of these searches, providing the search distributions overlap. Hence, the faster "yes" responses to category members for the pronunciation task and the faster "no" responses to nonmembers for the spelling task. Correct responses to pseudomembers can only be made on the basis of the outcome of one of the two searches and are therefore slower than their comparisons. Meyer and his colleagues (Meyer \& Ruddy, Note 4; Meyer \& Gutschera, Note 5) therefore conclude that phonological recoding occurs when decisions based on the semantic properties of words are required.

A further experiment reported by Meyer and Gutschera (Note 5) is also of interest since it is perhaps more similar to the lexical decision task. In this experiment they had subjects classify letter strings following the questions, "Is this a word?" and "Does this sound like a word?" Three types of stimuli were again employed, this time of the form BONE, NALE, and HEAK, requiring "yes," "no," and "no" responses, respectively, to the first question and "yes," "yes," and "no" responses, respectively, to the second question. Somewhat different results were obtained in this task than in the one reported above. The major difference was that "yes" decisions to category members were identical in the two tasks. They point out that if phonological recoding were occurring and if the phonological search sometimes finished before the graphemic search, then a difference between "yes" decisions to category members should have been evident as it was in the previous task. Since no such difference was observed and since the decision times in the pronunciation task were proportionately much slower compared with the spelling task in this experiment than in the previous one, Meyer and Gutschera argue that these results suggest that spelling decisions in this task are carried out on the basis of graphemic information alone, since the decision can be made on the basis of familiarity, and that phonemic recoding is only required for the pronunciation task. If this is entirely true, "no" responses to NALE and HEAK in the spelling task should be the same since neither are graphemically familiar. While the difference between the two nonword types was not significant, pseudowords were $53 \mathrm{msec}$ slower than legal nonwords, a result in the same direction as that observed by Coltheart et al. (1977) and Rubenstein et al. (1971). Meyer and Gutschera (Note 5) suggest in a footnote that this difference may reflect an accidental graphemic similarity between pseudowords and real words rather than a phonemic one. Coltheart et al. (1977), however, included a control for this factor in their design and found that the difference in response times between the two types of nonwords nevertheless persisted. Clearly, then, we cannot accept Meyer and Gutschera's (Note 5) evidence against phonemic recoding without some hesitation.

An additional categorization study has recently been reported by Green and Shallice (1976). These researchers proposed that if phonological recoding occurs prior to lexical access, then the number of syllables in a word should affect the latency for making "true" and "false" decisions regarding that word's category membership. They observed no such effects in their data. However, since Forster and Chambers (1973) and Frederiksen and Kroll (1976) report no effects of syllable length on naming latencies where presumably phonological recoding of some sort is required for articulation, it is perhaps not surprising that the number-of-syllables variable had no effect in the Green and Shallice study. One cannot necessarily conclude from these data, as they do, that "meaning is accessed directly from visual form and does not normally involve prelexical phonological recoding" (Green \& Shallice, 1976, p. 756). It is still logically possible that phonology plays a role that is not reflected in the number of syllables in a word.

Two final studies, both opposing the phonological recoding hypothesis, must be mentioned: that by Baron (1973) and that by Bower (1970). Bower's study required Greek-English bilinguals to translate a modified Greek text into English. The text had been altered such that, while maintaining correct pronunciations, many of the words were visually 
changed to pseudowords analogous in English to changing PHYSIOLOGY to FISIOLOGY. Bower found that his subjects took much longer to translate the altered text into English and thereby concluded that phonological recoding does not normally occur. As Meyer et al. (1974a) point out, however, it is possible to account for these results in other ways based on a visual "preprocessing" stage that might exert its effects before phonological recoding occurs. This problem of the visual unfamiliarity of pseudowords was avoided by Baron (1973) in a task that required subjects to classify phrases as "looking meaningful" or "sounding meaningful." He compared decision latencies to such phrases as (1) MY NEW CAR, which is visually and phonemically congruent with (2) MY KNEW CAR, which is phonemically but not visually congruent. Baron found that subjects required less time to indicate that Phrase 1 sounded meaningful than to indicate that Phrase 2 did and concluded that phonemic recoding does not normally occur. If it did, Baron argues, there shoud have been no difference between the two phrases since they are phonemically equivalent. Again, a possible objection is that the phrase MY NEW CAR is visually more familiar than the phrase MY KNEW CAR and this variable may exert its effect prior to phonological recoding. Baron also compared decision latencies to visually anomolous phrases such as OUR NO CAR and MY KNEW CAR when subjects were asked to respond to the question whether these phrases "looked meaningful." No difference in response latencies between the two phrases were observed, which Baron again interpreted to mean that phonological recoding was not in evidence. However, the subjects did in fact make more errors on the phrases that were phonemically congruent (MY KNEW CAR) and so a speed-accuracy tradeoff may have resulted. If so, a phonemic recoding hypothesis would not be entirely inconsistent with the data.

In summary, none of the reviewed studies have provided conclusive evidence concerning the nature of the lexical access code. It is the purpose of this paper to furnish data suggesting that phonemic recoding does indeed occur in the lexical decision task, and further, that such recoding is under the optional control of the subject.

\section{EXPERIMENT 1}

The first experiment followed from one performed previously in our laboratory. In that experiment, subjects were presented with simultaneous pairs of homophones (e.g., GROAN/GROWN) in a lexical decision task and decision latencies to these pairs were compared with latencies to nonhomophonic pairs (e.g., EARN/GROWN). Significantly faster reaction times were observed to the former pairs when compared with the latter. The difficulty with this experiment, however, was that, whenever two items had the same pronunciation, "yes" was always the correct response; hence, a nonlexical strategy was available here, and may have been responsible for the effect observed. Experiment 1 eliminated this difficulty by including a variety of "no" responses in which the letter strings also share the same sound (e.g., BRANE/BRAIN, WEEP/WEAP). The response in this experiment, therefore, could never be made on the basis of sound identity alone.

\section{Method}

Subjects. Thirty undergraduate students in either their first or second year at the University of Reading served as subjects. They were volunteers who were paid at the rate of 50 pence/h for their services.

Stimuli. The experiment comprised 28 practice trials plus 292 pairs of stimuli, the pairs being presented simultaneously with half the trials requiring a "yes" response and half a "no" response. Of the total trials, 42 were GROAN/GROWN pairs (the experimental trials) and 42 were EARN/GROWN pairs (the control trials); these were the stimuli of primary interest. A variety of control stimuli were constructed as follows: CHILD/MUSIC (60 pairs), so that subjects could not base "yes" decisions on the presence of a homophone; EIGHT/AIT (16 pairs), so that "yes" decisions could not be made on the basis of either the presence of a homophone or sound identity; FREND/FRIEND (14 pairs), BOSTE/FRIEND (14 pairs), WEED/WEAD (14 pairs), and LATE/WEAD (14 pairs) were also included, so that sound identity would not correlate with response type; and finally, 28 pairs of nonwords such as FROOT/DETH. Of all the stimuli that shared the same sound, 42 were "yes" responses and 60 were "no" responses. Of the 144 "yes" responses, 84 of the pairs included at least one homophone, while of the 148 "no" responses, 64 of the pairs included a homophone. It was felt that, therefore, this experiment adequately controlled for any possible confounding effects that might not involve lexical access. A complete list of the stimuli is presented in Appendix A.

Subjects were run in groups of one, two, three, or four. The stimuli were presented simultaneously to each subject on individual advance dual-trace $10-\mathrm{mHz}$ oscilloscopes (Type OS250) controlled by a PDP-12 computer. The stimuli were randomized such that half of the GROAN/GROWN pairs were displayed in the first half of the experiment and the other half in the second. Further, if GROAN/GROWN appeared in the first half, then EARN/GROWN appeared in the second, and similarly, GROAN/URN appeared in the first half and EARN/URN in the second. This procedure was adopted so that any effects due to the repetition of items (Scarborough et al., 1977) would be minimized.

The stimuli were presented one above the other in the center of the screen such that the initial letters of each string were directly aligned. They occupied a visual angle of $2.5 \mathrm{deg}$ horizontally and $1.5 \mathrm{deg}$ vertically. Two fixation points, one on either side of the positions occupied by the letter strings, preceded the presentation of the letter strings by $250 \mathrm{msec}$ and remained on the screen for $250 \mathrm{msec}$. The letter strings were then presented and remained on all the screens until each subject had made a response. Following the slowest response, the stimuli were removed from the screens and a period of $500 \mathrm{msec}$ intervened before the fixation points reappeared, signaling the next trial. Subjects were asked to make a "yes" response with their preferred index finger by pressing a key if both the letter strings were words and to make a "no" response with their nonpreferred index finger by pressing a different key if either or both of the letter strings were nonsense 
items. They were requested to make their responses as quickly and as accurately as possible. The computer recorded the response latencies and accuracy of the responses individually for each subject.

Data treatment and analysis. The data were treated using the following procedure: If an error was made on the pair GROAN/GROWN, then for that subject the data from the control pair EARN/GROWN was also eliminated. In this manner, only the data from correctly classified matched pairs were included in the subsequent analysis. Further, any reaction time that fell more than 3 standard deviations (SD) away from the mean for that condition was also eliminated, again along with its matched pair. This procedure was carried out on a recursive basis until all the data to be considered lay within the 3-SD limit. As a result $2 \%$ of the correct experimental trials were eliminated.

The data were then analyzed using the means for each subject for each condition in a $t$ test for related pairs. A similar $t$ test was performed for the word pairs in each condition. The min $F^{\prime}$ procedure recommended by Clark (1973) was not employed in the analysis of these data or in the analysis of data to be reported subsequently, since the stimuli in none of the experiments were randomly selected. The experimental stimuli comprise homophones in each case and generally exhaust the entire population, thereby making the min $F^{\prime}$ procedure inappropriate.

\section{Results}

There was no significant difference in the response times between the two conditions, either for subjects $[\mathrm{t}(29)=1.09]$ or for words $[\mathrm{t}(41)=.73]$. The mean for the subjects in the experimental condition was $928 \mathrm{msec}$; in the control condition, it was $916 \mathrm{msec}$. For the words these means were 924 and $913 \mathrm{msec}$, respectively. There was therefore no suggestion in these data that phonological identity facilitated "yes" responses.

One possibility that was considered post hoc was based on a finding by Becker et al. (Note 2). They found that with successive presentations, if an item was preceded by a graphemically and phonemically similar item, such as DIME/TIME, differing only in the first letter, then reaction time to the second item was faster than compared to the same item preceded by a dissimilar item (e.g., DARN/TIME). Furthermore, Becker et al. also reported a marginal inhibition to the second of a pait of items that differed only in the last letter (e.g., PARK/PART) when compared with the same item preceded by a dissimilar item (e.g., MAP/PART).

The homophones used in the above experiment fell roughly into two groups: those that shared final similarity (such as COLONEL/KERNEL) and those that shared initial similarity (such as THROWN/THRONE). It is possible that the two groups of items may have shown effects similar to those observed by Becker et al. (Note 2) that may have cancelled out any overall effect. This possibility was examined and rejected; no such effects were evident in the data.

\section{EXPERIMENT 2}

The second experiment investigated the effects on response latency of "repeating" homophones successively with one item intervening between the homophone-pair members. Scarborough et al. (1977) found a facilitatory effect on response latency when a word or nonword was repeated in a lexical decision experiment. A similar decrease in response latency to the second item of a homophonic pair would suggest that phonology plays some part in its processing.

\section{Method}

Subjects. Thirty-three undergraduates participated in this experiment and were paid at the same rate and chosen from the same population as those in Experiment 1. No subject participated in both experiments.

Stimuli. The stimuli were arranged as follows: Twenty-seven pairs of homophones were presented such that one item, either a word or a nonword, intervened between the two members of a pair, for example, EIGHT-DRUG-ATE. The response times to the second member of a pair, that is, the response time to ATE, was compared with the response time to the final item in a control string, for example, TRY-BIRD-ROB, such that ATE and ROB were matched for both word frequency and part of speech. In addition, 26 strings of the type DUG-TREE-DUG were included in order to replicate the Scarborough et al. (1977) study and to compare the magnitude of their effect with that of the possible effect on homophones. In these strings, DUG were also matched with ROB for word frequency and part of speech.

These three types of strings were randomly distributed throughout the experiment, which also contained 80 filler items for a total of 323 trials. Forty of the filler items were homophones not used in the experimental condition and their paired members never appeared. These filler items were used in order to dissuade subjects from always expecting a homophone to be followed by its mate on the next trial but one. Finally, the homophone pairs were arranged so that 12 of the pairs had the higher frequency member presented first followed by the lower frequency member; for example, EIGHT (frequency $=104$ ) followed by ATE (frequency $=16$ ). In the remaining 15 pairs, the order was reversed so that the lowfrequency member appeared first in the sequence followed by its high-frequency mate. This arrangement of the homophone pairs was employed to avoid any possible confounding effects that may have resulted from always presenting either the highor low-frequency member in the same position in the sequence.

The overall stimulus probability was $2: 1$ in favor of "yes" responses, and all the nonwords were such that they were pronounceable but did not sound like English words (e.g., SLINT, LENSEL). The stimuli are listed in Appendix B.

Procedure. The procedure was identical to that reported for Experiment 1 except that the stimuli in this instance were presented one at a time.

Data treatment and analysis. The same procedure was employed as that reported for Experiment 1 with respect to the treatment of the raw data. The resulting means were then analyzed in two separate two-way analyses of variance, one comparing the homophone repetition items with their controls and the other comparing the Scarborough etal. (1977) repetition-type items with the same controls. The second factor in both cases was the frequency-order factor.

\section{Results}

The reaction time (RT) and error data for subjects are shown in Table 1.

The results of the analysis of variance for subjects comparing the effect of homophone repetition with their controls revealed a significant interaction between the type of item (i.e., homophone vs. control) and the frequency-order factor $[F(1,32)=92.32, p<.001]$. A 
Table 1

Mean Reaction Time (RT) in Milliseconds and Error Percentages (\%E) for Each Conditions for Subjects in Experiment 2

\begin{tabular}{|c|c|c|c|c|}
\hline & \multicolumn{4}{|c|}{ Order } \\
\hline & \multicolumn{2}{|c|}{ High-Low } & \multicolumn{2}{|c|}{ Low-High } \\
\hline & RT & $\% \mathrm{E}$ & RT & $\% \mathbf{E}$ \\
\hline Controls & 577 & 13 & 491 & 3 \\
\hline Homophones & 540 & 10 & 523 & 4 \\
\hline Scarborough et al. (1977) replication & 511 & 3 & 490 & 4 \\
\hline
\end{tabular}

Note-High-low indicates high-frequency member of pair followed by low-frequency member; low-high indicates opposite order.

subsequent test for the simple main effect of type of item across individual levels of frequency order showed that when the homophones were the high-frequency members of a pair and occurred in the low-followed by the high-frequency order, then the RTs to these items were significantly slower than RTs to their controls [i.e., 523 vs. $491 \mathrm{msec}, F(1,32)=16.06, \mathrm{p}<.01$ ] Interestingly, the opposite effect was evident when type of item was examined across the high-to-low frequency ordering. In this case, RTs to the homophones were significantly faster than to their controls [i.e., 540 vs. $577 \mathrm{msec}, F(1,32)=7.99, \mathrm{p}<.011$. The analyses of variance for words revealed identical effects. Once more, the interaction between type of item and frequency order was significant $[F(1,25)=12.40$, $p<.01]$, as were the analyses of the simple main effects of type of item across frequency order [for low-to-high frequency order, $F(1,11)=5.14, p<.05$; for high-to-low frequency order, $F(1,14)=9.32$, $p<.01]$. The pattern of the error data demonstrates that the high error rates were associated with the slowest RTs and therefore indicates that a speed-accuracy tradeoff can be rejected as a possible explanation of the data.

The analyses of variance comparing the control items with repeated items as in the Scarborough et al. (1977) experiment showed a similar pattern of results to those obtained by those authors. A significant interaction was observed between type of item and frequency for both subjects and words $[F(1,32)=56.40$, $\mathrm{p}<.01$, for subjects; $\mathrm{F}(1,25)=17.97, \mathrm{p}<.01$, for words]. Tests of the simple main effect of repetition across low-frequency items demonstrated that RTs to repeated low-frequency items were significantly faster than to their controls [i.e., 511 vs. $577 \mathrm{msec}$, $F(1,32)=95.00, p<.01$, for subjects; 511 vs. $590 \mathrm{msec}$, $\mathrm{F}(1,11)=32.36, \mathrm{p}<.01$, for words] . This effect was not significant for repeated items of high frequency [490 vs. $491 \mathrm{msec}, \mathrm{F}(1,32)=.02$, for subjects; 494 vs. $494 \mathrm{msec}, F(1,14)=.00$, for words]. The error data again indicated that the slowest response times were associated with the highest error rates, denying a speedaccuracy tradeoff explanation.
Rather than attempt a detailed explanation of the homophone repetition effect at this point, let us simply say that these data suggest evidence for phonological recoding in the lexical decision task. If this is so, then an obvious question to ask is why should such an effect have been evident in Experiment 2 and absent in Experiment 1? The following two experiments attempted to examine this question.

\section{EXPERIMENTS 3 AND 4}

When we considered the differences between the first and second experiments, one possible explanation occurred to us that was vital to investigate if a useful model of word recognition were to be constructed. It seemed to us that an important difference lay in the nature of the nonwords employed in each case. In Experiment 1 the nonwords were all of the BRANE variety, while in Experiment 2 they were all of the SLINT type. It is therefore entirely possible that the subjects in Experiment 1 avoided the use of phonological recoding, since this procedure produced errors for all the nonwords. This would not be the case in Experiment 2; there, subjects could use phonological recoding if they chose to do so with perfect accuracy. It may well be that the difference in the results between the two experiments reflects a difference in strategies. The final two experiments investigated this possibility.

\section{Method}

The same design was used for both experiments, the difference between them lying in the fact that only the lowfrequency members of homophone pairs served as word stimuli in Experiment 3, while only the high-frequency members of the same pairs served as stimuli in Experiment 4. The stimuli in both experiments were otherwise identical.

The design comprised three segments. In the first segment the stimuli consisted of 29 homophones, 29 control words of identical word frequency and part of speech, and 40 nonwords of the SLINT type. These stimuli were presented in a different random order for each group of subjects (groups ranged in size from two to four). The second section consisted of 40 items, 20 words, and 20 nonwords, presented in a fixed order such that 10 words mixed with 10 SLINT nonwords occurred first followed by 10 words and 10 GRONE nonwords. This section was included for ease of analysis so that all subjects received the identical first 10 GRONE nonwords. The final section consisted of another 30 homophones and 30 control words along with a further 40 GRONE-type nonwords. The items in the last section were also presented in a different random order for each group of subjects.

The stimuli were presented successively, as in Experiment 2, from beginning to end with no discrete event signaling a change in sections to the subjects. A list of the stimuli for each experiment is shown in Appendix C.

The purpose of the design was to allow subjects to use a phonological strategy in the first part of the experiment with perfect accuracy. If subjects chose to do so, some effect might be observed on the low-frequency homophone-pair members compared with their controls in Experiment 3. Indeed, we predicted that response times to these items would be faster than to their controls, since a visual recheck is unnecessary when phonology is always correct and the high-frequency member 
of a pair might be accessed for comparison first, resulting in faster response times. Such a phonological strategy might also result in a larger number of errors on the first 10 GRONE nonwords compared with the preceding 10 SLINT nonwords. Further, if subjects became aware that phonology in the final section of the experiment produced errors on the nonwords, they might abandon such a strategy and perhaps rely more on the visual characteristics of the stimuli as a basis for their responses. If this were the case, the final section of Experiment 3 would show no difference in response times to the homophones and their controls, since homophony per se would no longer be beneficial.

Experiment 4, in which only the high-frequency members of the same homophone pairs appeared, served as a control experiment. We wished to be certain that the high-frequency members showed no difference from their controls in either a SLINT or a GRONE nonword environment. If these items also showed faster response times than their controls, then such an effect would be important to the construction of any subsequent models.

Subjects. Thirty-seven subjects served in Experiment 3 and 33 served in Experiment 4. The subjects were chosen from the same population and paid at the same rate as those in the previous experiments. No subject participated in both experiments, and none had served in either of the previous experiments.

\section{Results}

The same procedure was used to deal with the raw data as that reported for the previous experiments, and the resulting means and error rates are shown in Table 2.

Experiment 3. A series of correlated $t$ tests was performed comparing the RTs to the homophones in each part of the experiment with their respective controls, both for the subjects and for the words. For subjects, a significant difference was observed in the first part of the experiment between the homophones and their controls [628 vs. $606 \mathrm{msec}, \mathrm{t}(36)=3.17, \mathrm{p}<.05]$. Contrary to expectation, RTs to the homophones in the SLINT condition were significantly slower than RTs to their controls. A similar effect was evident in the analysis for the words [635 vs. $611 \mathrm{msec}$, $\mathrm{t}(28)=1.83, \mathrm{p}<.05]$.

The homophones in the GRONE nonword condition, however, showed no.difference in RT to the controls in the final section of the experiment for subjects or for words [for subjects, 600 vs. $596 \mathrm{msec}, \mathrm{t}(36)=.61$; for words, 605 vs. $600 \mathrm{msec}, \mathrm{t}(29)=.38$ ]

A comparison of the error rates on the nonwords in the middle section demonstrated that the average error rate increased from $4 \%$ on the final 10 SLINT nonwords to $16 \%$ across the first 10 GRONE nonwords. Unfortunately, these items were not controlled for visual similarity and, therefore, this result must be interpreted with some caution.

Experiment 4. None of the $t$ tests comparing RT between the homophones and their controls revealed any significant differences for subjects or for words in this experiment. The error rates in the middle section across the nonwords showed a similar pattern to that observed in Experiment 3 with a rate of $3 \%$ across
Table 2

Mean Reaction Time (RT) in Milliseconds and Percent Errors (\%E) Across Conditions for Subjects in Experiments 3 and 4

\begin{tabular}{ccccccc}
\hline \multirow{2}{*}{$\begin{array}{c}\text { Experi- } \\
\text { ment }\end{array}$} & & \multicolumn{2}{c}{ Homophones } & & \multicolumn{2}{c}{ Controls } \\
\cline { 3 - 4 } \cline { 5 - 6 } & & RT & $\%$ E & & RT & $\%$ E \\
\hline \multirow{2}{*}{3} & SLINT & 628 & 9 & 606 & 3 \\
& GRONE & 600 & 0 & 596 & 3 \\
4 & SLINT & 585 & 3 & 591 & 6 \\
\hline
\end{tabular}

SLINT nonwords increasing to a rate of $8 \%$ across the GRONE nonwords. Again, caution must be employed to interpret this increase.

\section{DISCUSSION}

This paper has attempted to discover evidence for the phonological encoding of words in the lexical decision task. More specifically, it has investigated this question by comparing response latencies to homophones with response latencies to control words. To briefly summarize the results, in Experiment 1 no effect of homophony was observed for words, while in Experiment 2 such an effect for words was clearly evident. One of the differences between the two experiments lay in the type of nonword employed: The former presented the subjects only with pseudohomophones such as BRANE, while the latter presented only SLINTtype nonwords. It seemed quite possible, therefore, that subjects could employ a phonemic strategy successfully in Experiment 2 if they chose to do so, but not in Experiment 1, thereby accounting for the contradictory results obtained with words. Experiment 3 tested this hypothesis and demonstrated an effect of phonology on the less frequent member of a pair of homophones compared with control items when the nonword distractors were of the SLINT type, but not when they were changed to the GRONE type. The final experiment reported was a control experiment that demonstrated that the type of nonword distractor did not differentially affect response latencies to the high-frequency members of the homophone pairs used in Experiment 3, as compared with controls.

We would like to consider the results of the above experiments within the framework of the logogen model of word recognition proposed by Morton (1969). Briefly, this model assumes the existence of a set of neural devices termed "logogens" that accept information, regardless of source, concerning particular word responses. When a sufficient amount of information has been accumulated within a particular logogen, that logogen passes its threshold value and the corresponding word response becomes available. This paper is concerned with the manner in which the sources of information accumulate in making available the appropriate responses. 
The model previously outlined (Coltheart et al., 1977) attempted to provide a description of the lexical access procedure by postulating a parallel access, logogen-like model with a variable deadline for producing negative responses. Such a procedure adequately accounted for the data reported in the earlier paper. We did not, at that time, offer an answer to the question concerning the nature of the lexical access code, apart from suggesting that visual and phonological inputs to the lexicon cooperate in locating an entry, rather than competing in a race-like fashion, as has been suggested by Meyer and Ruddy (Note 4) and Meyer and Gutschera (Note 5). We will attempt to do so in what follows, couching our discussion in terms of the direct lexical access procedure described in the earlier paper.

It seems to us that an explanation in which decisions as to lexicality may sometimes be based on the outcome of a phonological encoding procedure and sometimes on on the outcome of a graphemic encoding procedure would most satisfactorily account for all of the observed effects. The model we wish to propose maintains the simultaneous graphemic and phonemic encoding procedures but interprets the interplay between these procedures not simply as a race but as a race in which one of the procedures suffers from an adjustable handicap. This model incorporates three features not all found in any previous model: (1) an optional phonological encoding strategy under the control of the subject, (2) a visual recheck procedure following lexical access, and (3) a temporary response inhibition in the case of homophones when the incorrect member of a pair has been accessed. Let us examine these ideas in the context of the above results.

With respect to the first feature, an optional encoding procedure, we make this suggestion to account for the fact that, while effects of phonology were evident when SLINT nonwords were present as distractors, these effects were entirely absent when the distractors consisted of GRONE nonwords. The differential effect can be explained if we postulate that the subject is able to decide on the basis of accuracy in the first few trials whether to rely on the outcome of the phonemic as well as the graphemic encoding procedures. If many GRONE nonwords are present, a phonological strategy would produce many errors, while a graphemic strategy would not. The subject therefore abandons the use of phonological encoding. In this case, no effect of phonology should be evident in the presence of GRONE nonwords; and this is what we observed. The converse, however, is not true. It is not the case that reliance on graphemic encoding should ever produce errors, so this strategy would appear to be optimal in all cases. However, phonological effects were consistently observed in the presence of SLINT nonwords, and we therefore conclude that naive subjects in performing this task rely on the outcome of phonological encoding as well as visual encoding, and continue this strategy throughout if it is found to be successful; they will, however, abandon the phonological strategy as soon as an unacceptable level of errors occurs, as in the second half of Experiment 3 when the nonwords were changed from SLINTs to GRONEs. Note that we do not wish to suggest that in the event decisions as to lexicality are based on phonological encoding, the visual encoding procedure is inactive. Rather, we would maintain that both encoding procedures occur simultaneously, with the subjects relying on the phonological outcome in the event SLINT nonwords comprise the distractors. We would therefore wish to characterize the relationship between graphemic and phonemic encoding procedures not simply as a race, but one in which the outcome of the phonological procedure is handicapped such that it is either slowed down or ignored when it produces a large number of erroneous decisions.

The fact that the type of nonword distractors affects processing in the lexical decision task has been demonstrated previously by James (1975). In a series of experiments, he reported that the use of pronounceable, legal nonwords such as both SLINT and BRANE produced an interaction on response latencies between word frequency and concreteness. When illegal nonwords such as NTISL were used instead, or if the subjects were familiarized with the words to be used in the task beforehand, the interaction disappeared. James (1975) attributed these results to differences, not in strategies, but in the depth of processing required in the different situations. He argued that the degree of similarity between words and nonwords determines the criteria for responding such that if similarity is high, the response criterion for low-frequency words requires semantic information (concreteness) for a response, while if similarity is low, this criterion is relaxed and lexical retrieval alone can be sufficient for a response. The data presented in the present paper suggest that the type of nonword distractor also determines the kind of processing the subjects may opt to employ.

Similar strategy differences have also recently been reported by Hawkins, Reicher, Rogers, and Peterson (1976) in a tachistoscopic word-recognition task. These authors found that accuracy of report was lower for homophones if the stimulus list contained a low proportion of homophones than if the list contained a high proportion of homophones. In the former situation, reliance on phonemic information would lead to accurate performance on most of the items except for the occasional homophone. In the latter case, reliance on phonology would result in a high proportion of errors. From their results, Hawkins et al. (1976) conclude that a difference in strategy was observed in the two groups of subjects with the former relying on phonemic information and the latter on "visual or perhaps semantic codes." These results are compatible with those presented above.

The postulation of an optional encoding strategy 
does not, however, explain all of the observed effects. Why, for example, were the low-frequency members of the homophone pairs in Experiment 3 slower than their controls rather than faster, as might be expected if their high-frequency counterparts were accessed first on the basis of phonological encoding? To account for this result, we suggest that following any phonologically mediated lexical access, a visual spelling recheck procedure is carried out in order to avoid erroneous "yes" responses to pseudohomophones. In the case where the item is a homophone and two entries are accessed, this recheck procedure is carried out serially with the high-frequency item being examined first.

We take the view that the lexical entries themselves, however, are accessed in parallel, rather than serially in order of frequency as proposed by Rubenstein et al. (1971); our reasons for taking this view are given elsewhere (Coltheart et al., 1977). Thus the two lexical entries corresponding to the two words of a homophonic pair are accessed in parallel by the phonological code derived from either member of the pair. Since, however, the time required for a logogen to reach threshold is postulated to be inversely related to word frequency, the more frequent member of a homophone pair will usually reach threshold before the less frequent member on the basis of phonological input to the lexicon, regardless of which member of the pair is actually present as the stimulus.

Whenever a threshold is reached, a spelling check is carried out. If this is successful, the word present has been identified and a positive response is made. If the spelling check fails, no response is made, since the failure of a spelling check could occur in response to a word (i.e., the low-frequency member of a homophonic pair) or in response to a nonword (e.g., BRANE). As previously outlined, we maintain the notion that negative responses are generated only when a variable deadline has elapsed and in no other way.

The mechanism by which the postulated spelling checks are performed must possess the property that it cannot perform more than one such check at a time. Given this property, "yes" responses to low-frequency homophones will be delayed because they will have to wait for their spelling checks until the spelling checks on the high-frequency member (which reaches threshold earlier) has been completed. Control words of the same frequency as the low-frequency homophones will not incur the waiting time and so will yield faster "yes" responses. Thus, although access using the phonological code is parallel, use of the spelling check mechanism is serial, with the high-frequency member checked first because it reaches threshold earlier. This explains why, when phonological access is occurring (i.e., when nonwords are of the SLINT type), low-frequency homophones have slower "yes" times than their controls, while high-frequency homophones do not (Experiments 3 and 4).
The third process we need to complete the explanation of the results of these four experiments is an inhibition generated by an unsuccessful spelling check. Suppose that, if a lexical entry is accessed via a phonological code and a spelling check is carried out, whenever this check fails, indicating that the wrong entry has been accessed, the availability of the entry is temporarily reduced. Inhibitory effects of this kind have been postulated by Neill (1977) and Lowe (Note 6).

Both Neill (1977) and Lowe (Note 6) report data from Stroop-type situations in which subjects were required to name ink color of printed color words (e.g., RED might be printed in blue ink, BLUE might be printed in green ink, GREEN might be printed in black ink, and so on; correct responses would be "blue," "green," and "black," respectively). In this situation subjects were slower to say "blue" to an item printed in blue ink if it had been preceded by the word BLUE printed in a different color than if any other color word had preceded it. The suggested explanation is that subjects perform this task by suppressing the name of the word presented, thereby making it less available for a response when it is required on an immediately subsequent trial.

An effect of this kind predicts the interaction we observed in Experiment 2 between the order in which two homophones were presented and the direction of the influence of the first homophone on response time to the second. Consider first the situation when the high-frequency homophone is the first presented. The first lexical entry excited via phonological encoding will be the correct one and the spelling check will succeed, no further spelling check is needed and the subject simply responds "yes." Phonological input will have at least partially excited the entry for the other member of the homophone pair, and so when this other member is actually presented (on the next trial but one), access to its entry will be facilitated. Thus prior presentation of a high-frequency homophone will facilitate the "yes" response to subsequent presentation of the low-frequency homophone, as we found.

Now consider what happens if it is the low-frequency member that is presented first. On this trial, the wrong lexical entry will be excited by phonological input, and the subsequent spelling check will fail; an inhibitory effect on this entry will therefore be generated. When, two trials later, the word that corresponds to this entry is presented, access to the entry will therefore be impeded. Thus prior presentation of a low-frequency homophone will impair the "yes" response to subsequent presentation of the high-frequency homophone, as we found.

A recent paper by Warren and Warren (1976) provides additional support for the notion that both lexical entries of a homophone are activated when only one of the pair has been presented, either auditorily 
or visually. Using a modified Brown-Peterson paradigm, they auditorily presented subjects with triads such as helpless-wik-fragile followed by year-month-decade. The homophone "wik" was the item of interest since WEAK was appropriate in the former triad and WEEK was a possible category member in the latter. The test subjects showed a significantly greater number of homophone intrusions (i.e., WEEK) in their recall of the second triad than control subjects. A similar pattern of intrusions was observed when the triads were presented visually (e.g., plunged-jumped-dove followed by pigeon-sparrow-robin). Warren and Warren (1976) concluded that their data suggest that both members of a homophonic pair are activated in the lexicon when only one has been presented, and that this activation persists long enough to influence intrusion patterns when the subject performs a search of activation in the logogen system when the three items required for recall are no longer in operational memory. Our data also suggest that the presentation of one member produces activation in the lexical entries for both members.

In summary then, we would like to extend our previous outline of the lexical access code and procedure to include the above features. We would also point out that models based solely on either graphemic or phonemic encoding alone are unable to account for the observed effects.

Appendix A

Test Stimuli for Experiment

\begin{tabular}{lll}
\hline alter/altar & wine/whine & tow/toe \\
packed/pact & build/billed & heal/heel \\
earn/urn & horse/hoarse & wring/ring \\
weighed/wade & manner/manor & waive/wave \\
pause/paws & hare/hair & yolk/yoke \\
border/boarder & sighs/size & fowl/foul \\
cellar/seller & bale/bail & dyed/died \\
flower/flour & prey/pray & cite/sight \\
ceiling/sealing & reign/rain & pore/pour \\
colonel/kernel & fare/fair & vale/veil \\
thrown/throne & deer/dear & boar/bore \\
steel/steal & beech/beach & chute/shoot \\
tied/tide & gait/gate & fur/fir \\
waste/waist & gilt/guilt & flair/flare \\
\hline
\end{tabular}

Appendix B

Test Stimuli for Experiment 2

High-followed by low-frequency pairs

\begin{tabular}{|c|c|c|}
\hline $\begin{array}{l}\text { flour-choir-peaks } \\
\text { tide-drum-tomb } \\
\text { taut-sane-meek } \\
\text { ate-dug-rob }\end{array}$ & $\begin{array}{l}\text { altar-donor-coral } \\
\text { pact-bump-cart } \\
\text { manor-eagle-easel } \\
\text { scent-brute-frost }\end{array}$ & $\begin{array}{l}\text { kneed-bleat-droop } \\
\text { fare-bang-bulb } \\
\text { hole-mine-drop } \\
\text { rode-hate-wire }\end{array}$ \\
\hline \multicolumn{3}{|c|}{ Low-followed by high-frequency pairs } \\
\hline $\begin{array}{l}\text { pale-roof-snow } \\
\text { one-her-all } \\
\text { pain-king-loss } \\
\text { rain-song-dust } \\
\text { great-three-small }\end{array}$ & $\begin{array}{l}\text { grown-feels-holds } \\
\text { ring-cook-milk } \\
\text { mayor-guide-grace } \\
\text { sale-bond-salt } \\
\text { hall-food-wall }\end{array}$ & $\begin{array}{l}\text { horse-heart-space } \\
\text { which-these-first } \\
\text { seem-turn-cost } \\
\text { bear-spot-wage } \\
\text { rose-loss-post }\end{array}$ \\
\hline
\end{tabular}

Note-The triads are arranged in the following order: 11 the item presented second of the homophone pairs; (2) the Scarborough repeated words; (3) the control words.
Appendix C

Test Stimuli for Experiments 3 and 4

\begin{tabular}{llll}
\hline SLINT* & GRONE** & SLINT* & GRONE** \\
\hline aloud & sum & sail & knight \\
altar & throne & seam & threw \\
beech & maid & sighed & write \\
boarder & shore & steal & rode \\
seller & hour & suite & deer \\
kernel & scene & tide & gilt \\
urn & sea & waist & grate \\
flour & sighs & weak & feat \\
guessed & taut & whine & groan \\
hare & witch & haul & reign \\
hire & wood & hear & pear \\
lone & hoarse & herd & chute \\
manor & nun & hymn & weigh \\
pact & blew & leased & sole \\
paws & ate & & scent \\
\hline
\end{tabular}

*These items appeared in the SLINT-nonword environment in Experiment 3 and their paired high-frequency members appeared in the same environment in Experiment 4.

**These items appeared in the GRONE-nonword environment in Experiment 3 and their paired high-frequency members appeared in the same environment in Experiment 4.

\section{REFERENCE NOTES}

1. Scarborough, D. L., \& Springer, L. Noun-verb differences in word recognition. Paper presented at the meeting of the Psychonomic Society, St. Louis, Missouri, November 1973.

2. Becker, C. A., Schvaneveldt, R. W., \& Gomez, L. M. Semantic, graphemic, and phonetic factors in word recognition. Paper presented at the 14th meeting of the Psychonomic Society, St. Louis, Missouri, November 1973.

3. Coltheart, M., Jonasson, J.. Davelaar, E., \& Besner, D. Phonological encoding in the lexical decision task. In preparation.

4. Meyer, D. E., \& Ruddy, M. G. Lexical memory retrieval based on graphemic and phonemic representations of printed words. Paper presented at the meeting of the Psychonomic Society, St. Louis, Missouri, November 1973.

5. Meyer, D. E., \& Gutschera, K. D. Orthographic vs. phonemic processing of printed words. Paper presented at the meeting of the Psychonomic Society. Denver, Colorado, November 1975.

6. Lowe, D. Personal communication, 1975.

\section{REFERENCES}

BARON. J. Phonemic stage not necessary for reading. Quarterly Journal of Experimental Psychology, 1973, 25, 241-246.

Bloomfield, L. Linguistics and reading. Elementary English, $1942,19,125-130$

Bower, T. G. R. Reading by eye. In H. Levin \& J. P. Williams (Eds.), Basic studies on reading. New York: Basic Books, 1970. Clark, H. H. The language-as-fixed-effect fallacy: A critique of language statistics in psychological research. Journal of Verbal Learning and Verbal Behavior, 1973, 12, 335.359.

Cohen, G., \& Freeman, R. Individual differences in reading strategies in relation to handedness and cerebral asymmetry. In J. Requin (Ed.), Attention and performance VII. Hillsdale, N.J: Lawrence Erlbaum, in press.

Coltheart. M., Davelaar, E., Jonasson, J., \& Besner, D. Access to the internal lexicon. In S. Dornic (Ed.), Attention and performance VI. Hillsdale, N.J: Lawrence Erlbaum, 1977.

Forster, K. J.. \& Chambers. S. M. Lexical access and naming time. Journal of Verbal Learning and Verbal Behavior, 1973 12. 627-635.

Frederiksen, J. R., \& Kroll. J. F. Spelling and sound: Approaches to the internal lexicon. Joumal of Experimental 
Psychology: Human Perception and Performance, 1976, 2 , 361-379.

Gough, P. B. One second of reading. In J. F. Kavanagh \& J. G. Mattingly (Eds.), Language by ear and by eye. Cambridge, Mass: M.I.T. Press, 1972.

Green, D. W., \& Shallice, T. Direct visual access in reading for meaning. Memory \& Cognition, 1976, 4, 753-758.

Hawkins, H. L., Reicher, G. M., Rogers, M., \& Peterson, L. Flexible coding in word recognition. Journal of Experimental Psychology: Human Perception and Performance, 1976, 2, 380-385.

JAMES, C. T. The role of semantic information in lexical decisions. Journal of Experimental Psychology: Human Perception and Performance, 1975, 1, 130-136.

Kolers, P. A. Three stages in reading. In $H$. Levin \& J. P. Williams (Eds.), Basic studies in reading. New York: Basic Books, 1970.

Marcel, A. J., \& Patterson, K. Word recognition and production: Reciprocity in clinical and normal studies. In J. Requin (Ed.), Attention and performance VII. Hillsdale, N.J: Lawrence Erlbaum, in press.

Meyer, D. E., Schvaneveldt, R. W., \& Ruddy, M. G. Functions of graphemic and phonemic codes in visual word recognition. Memory \& Cognition, 1974, 2. 309-321. (a)
Meyer, D. E., Schvaneveldt, R. W., \& Ruddy, M. G. Loci of contextual effects on visual word recognition. In P. M. A. Rabbitt \& S. Dornic (Eds.), Attention and performance $V$. New York: Academic Press, 1974. (b)

Morton, J. Interaction of information in word recognition. Psychological Review, 1969, 76, 165-178.

NeILL, W. T. Inhibitory and facilitatory processes in selective attention. Journal of Experimental Psychology: Human Perception and Performance, 1977, 3, 444-450.

Rubenstein, H., Lewis, S. S., \& Rubenstein, M. A. Evidence for phonemic recoding in visual word recognition. Journal of Verbal Learning and Verbal Behavior, 1971, 10, 645-657.

Scarborough, D. L.. Cortese, C., \& Scarborough, H. S. Frequency and repetition effects in lexical memory. Jourmal of Experimental Psychology: Human Perception and Performance, $1977,3,1-17$.

WARREN, R. E., \& WARREN, N. T. Dual semantic encoding of homographs and homophones embedded in context. Memory \& Cognition, 1976, 4, 586-592.

(Received for publication December 7, 1977; accepted May 18, 1978.) 